OPEN ACCESS

Edited by:

Changjun Li,

Central South University, China

Reviewed by:

Ye Xiao,

Central South University, China

Gaofeng Xiong,

University of Kentucky, United States

*Correspondence:

Qiong LU

christy_luq@csu.edu.cn

Ren Wu

wurenraul@csu.edu.cn

${ }^{\dagger}$ These authors have contributed equally to this work

Specialty section:

This article was submitted to

Molecular Medicine,

a section of the journal

Frontiers in Cell and Developmental

Biology

Received: 03 March 2021

Accepted: 03 May 2021

Published: 26 May 2021

Citation:

Li H, Qu J, Zhu H, Wang J, He H, Xie X, Wu R and Lu Q (2021) CGRP Regulates the Age-Related Switch Between Osteoblast and Adipocyte

Differentiation.

Front. Cell Dev. Biol. 9:675503. doi: 10.3389/fcell.2021.675503

\section{CGRP Regulates the Age-Related Switch Between Osteoblast and Adipocyte Differentiation}

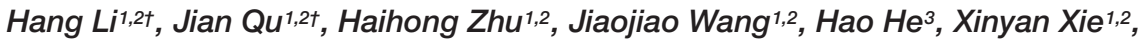 \\ Ren $W u^{4 *}$ and Qiong $L u^{1,2 *}$ \\ ${ }^{1}$ Department of Pharmacy, The Second Xiangya Hospital of Central South University, Changsha, China, ${ }^{2}$ Institute of Clinical \\ Pharmacy, Central South University, Changsha, China, ${ }^{3}$ Department of Vascular Surgery, The Second Xiangya Hospital \\ of Central South University, Changsha, China, ${ }^{4}$ Department of Orthopedics, The Second Xiangya Hospital of Central South \\ University, Changsha, China
}

Osteoporosis is a chronic age-related disease. During aging, bone marrow-derived mesenchymal stem cells (BMSCs) display increased adipogenic, along with decreased osteogenic, differentiation capacity. The aim of the present study was to investigate the effect of calcitonin gene-related peptide (CGRP) on the osteogenic and adipogenic differentiation potential of BMSC-derived osteoblasts. Here, we found that the level of CGRP was markedly lower in bone marrow supernatant from aged mice compared with that in young mice. In vitro experiments indicated that CGRP promoted the osteogenic differentiation of BMSCs while inhibiting their adipogenic differentiation. Compared with vehicle-treated controls, aged mice treated with CGRP showed a substantial promotion of bone formation and a reduction in fat accumulation in the bone marrow. Similarly, we found that CGRP could significantly enhance bone formation in ovariectomized (OVX) mice in vivo. Together, our results suggested that CGRP may be a key regulator of the age-related switch between osteogenesis and adipogenesis in BMSCs and may represent a potential therapeutic strategy for the treatment of age-related bone loss.

Keywords: CGPR, osteoporosis, BMSCs, osteogenic, adipogenic, age-related

\section{INTRODUCTION}

Osteoporosis is a chronic disease caused by the breakdown of bone homeostasis, with elderly and postmenopausal women being the populations most at risk of developing this condition (NIH Consensus Development Panel on Osteoporosis Prevention, Diagnosis, and Therapy, 2001; Rachner et al., 2011). Age-related bone loss and osteoporosis have been associated with reduced numbers of osteoblasts and increased numbers of adipocytes (Idris et al., 2009; Yu and Wang, 2016). It is known that bone marrow mesenchymal stem cells (BMSCs) have the potential to differentiate into osteoblasts, adipocytes, and osteoclasts, thereby playing an important role in bone formation (Li et al., 2016; Chen et al., 2018; Peng et al., 2019). Overall, bone homeostasis depends on the balance between the osteogenic and adipogenic differentiation of BMSCs (Li et al., 2015; 
Lv et al., 2018). Age-related osteoporosis results from reduced osteogenic differentiation and increased adipogenic differentiation of BMSCs in elderly patients (Shen et al., 2012; Childs et al., 2015; Li et al., 2017).

Calcitonin gene-related peptide (CGRP), a member of the calcitonin protein family, is a 37 -amino acid peptide generated through the alternative splicing of primary transcripts of the calcitonin gene (Amara et al., 1982; Rosenfeld et al., 1983; Naot and Cornish, 2008). In humans and mice, CGRP exists as two isoforms- $\alpha$-CGRP and $\beta$-CGRP-which are encoded by the $C A L C A$ and $C A L C B$ genes, respectively. In mice, $\alpha$-CGRP is highly expressed in the central nervous system and peripheral nervous system, while $\beta$-CGRP is expressed in the enteric nervous system (Sternini, 1992; Russell et al., 2014). In addition, in mice, the Calca gene has been shown to affect bone remodeling; however, the underlying mechanism remains unclear (Schinke et al., 2004).

CGRP is a neuropeptide that is released from sensory nerve endings and can also be found in bone cells and endothelial cells (Russell et al., 2014). There is evidence that CGRP is involved in the regulation of cell proliferation and differentiation, and may also be important for connecting the systems involved in bone metabolism (Bjurholm et al., 1988; Chattergoon et al., 2005; Thievent et al., 2005; Zhang et al., 2016; Xu et al., 2019). Additionally, studies have confirmed that CGRP can promote osteogenesis and inhibit osteoclast formation (Imai et al., 1997; Villa et al., 2003; Yoo et al., 2014). However, few studies have investigated the roles of CGRP in the agerelated switch between osteoblast and adipocyte differentiation in bone marrow. Consequently, the aim of this study was to investigate whether CGRP is associated with increased bone formation and inhibition of adipocyte accumulation in agerelated bone loss.

In the current study, we show that the level of CGRP in mouse bone marrow-derived supernatant decreases with aging. Furthermore, we found that CGRP not only promotes the osteogenic differentiation of BMSCs but also inhibits their adipogenic differentiation and senescence. Importantly, we demonstrate that exogenous application of CGRP can accelerate bone formation in aged and OVX mice in vivo, implying that CGRP may be a potential therapeutic target for the prevention of osteoporosis.

\section{MATERIALS AND METHODS}

\section{Mice}

C57BL/6JN mice were purchased from Hunan Slaccas Jingda (Changsha, China). Two-month-old female C57BL/6JN mice underwent bilateral ovarian resection to establish the OVX model. For in vitro CGRP treatment experiments, 12-monthold OVX mice and sham-operated mice were injected with CGRP (10 mg/kg) via the tail vein three times weekly for 1 month. Mice treated with $1 \times$ PBS were used as controls. All mice were maintained in the specific-pathogen-free facility of the Laboratory Animal Research Center of Central South University. The mice were kept under a 12 h/12 h light: dark
TABLE 1 | Primer pairs in this study.

\begin{tabular}{|c|c|c|}
\hline Name & Sequence $\left(5^{\prime}-3^{\prime}\right)$ & Amplicon size (bp) \\
\hline Gdpd2-F & CCAGCAAGTGCGACTGTATCT & 185 \\
\hline Gdpd2-R & GACCAGGAGAGAGACGACCA & \\
\hline $\operatorname{lgf1}-\mathrm{F}$ & CTGGACCAGAGACCCTTTGC & 269 \\
\hline lgf1-R & GGACGGGGACTTCTGAGTCTT & \\
\hline Fgf9-F & ATGGCTCCCTTAGGTGAAGTT & 104 \\
\hline Fgf9-R & TCATTTAGCAACACCGGACTG & \\
\hline Wnt10b-F & GCGGGTCTCCTGTTCTTGG & 71 \\
\hline Wnt10b-R & CCGGGAAGTTTAAGGCCCAG & \\
\hline Gli2-F & GGGACTCTTTAGCCTCGCAG & 158 \\
\hline Gli2-R & CCACAGGGTTGAGGTAGTCAT & \\
\hline Rspo2-F & CCAAGGCAACCGATGGAGAC & 100 \\
\hline Rspo2-R & TCGGCTGCAACCATTGTCC & \\
\hline Jag1-F & CCTCGGGTCAGTTTGAGCTG & 150 \\
\hline Jag1-R & CCTTGAGGCACACTTGAAGTA & \\
\hline Sox2-F & GCGGAGTGGAAACTITTGTCC & 157 \\
\hline Sox2-R & CGGGAAGCGTGTACTTATCCTT & \\
\hline Igfbp3-F & CCAGGAAACATCAGTGAGTCC & 101 \\
\hline lgfbp3-R & GGATGGAACTTGGAATCGGTCA & \\
\hline $\operatorname{lgf2-F}$ & GTGCTGCATCGCTGCTTAC & 222 \\
\hline $\operatorname{lgf2-R}$ & ACGTCCCTCTCGGACTTGG & \\
\hline Bmp8a-F & AGTCTCTGGTCAGTACCACAG & 160 \\
\hline Bmp8a-R & TGTTTACGCAGGATGACATTGTT & \\
\hline Bmp4-F & ATTCCTGGTAACCGAATGCTG & 89 \\
\hline Bmp4-R & CCGGTCTCAGGTATCAAACTAGC & \\
\hline Id $4-F$ & CAGTGCGATATGAACGACTGC & 72 \\
\hline ld4-R & GACTTCTTGTTGGGCGGGAT & \\
\hline Bmp6-F & AGAAGCGGGAGATGCAAAAGG & 211 \\
\hline Bmp6-R & GACAGGGCGTTGTAGAGATCC & \\
\hline Acvr2a-F & GCGTTCGCCGTCTITCTTATC & 108 \\
\hline Acvr2a-R & GTTGGTTCTGTCTCTTTCCCAAT & \\
\hline Pth1r-F & CAGGCGCAATGTGACAAGC & 125 \\
\hline Pth1r-R & TाTCCCGGTGCCTTCTCTTC & \\
\hline Lrp5-F & ACGTCCCGTAAGGTTCTCTTC & 172 \\
\hline Lrp5-R & GCCAGTAAATGTCGGAGTCTAC & \\
\hline Hdac5-F & AGCACCGAGGTAAAGCTGAG & 91 \\
\hline Hdac5-R & GCTGTGGGAGGGAATGGTT & \\
\hline Hey1-F & GCGCGGACGAGAATGGAAA & 231 \\
\hline Hey1-R & TCAGGTGATCCACAGTCATCTG & \\
\hline Dlk1-F & AGTGCGAAACCTGGGTGTC & 148 \\
\hline Dlk1-R & GCCTCCTTGTTGAAAGTGGTCA & \\
\hline Tmem119-F & ССTACTCTGTGTCACTCCCG & 212 \\
\hline Tmem119-R & CACGTACTGCCGGAAGAAATC & \\
\hline Fam20c-F & GATGTGACGCGGGATAAGAAG & 100 \\
\hline Fam20c-R & GCTCGGTGGAACAGTAGTAGG & \\
\hline Gja1-F & ACAGCGGTTGAGTCAGCTTG & 106 \\
\hline Gja1-R & GAGAGATGGGGAAGGACTTGT & \\
\hline Tgfbr3-F & GGTGTGAACTGTCACCGATCA & 125 \\
\hline Tgfbr3-R & GTTAGGATGTGAACCTCCCTTG & \\
\hline Col1a1-F & GCTCCTCTTAGGGGCCACT & 103 \\
\hline Col1a1-R & CCACGTCTCACCATTGGGG & \\
\hline Ift80-F & AGCTGTGTGGGTTGGACTAC & 107 \\
\hline Ift80-R & AGCTTGACTATTAGGCTGGTTC & \\
\hline Hmga2-F & GAGCCCTCTCCTAAGAGACCC & 106 \\
\hline
\end{tabular}

(Continued) 
TABLE 1 | Continued

\begin{tabular}{|c|c|c|}
\hline Name & Sequence (5'-3') & Amplicon size (bp) \\
\hline Hmga2-R & TTGGCCGTITTCTCCAATGG & \\
\hline Ptgs2-F & TGTGACTGTACCCGGACTGG & 233 \\
\hline Ptgs2-R & TGCACATTGTAAGTAGGTGGAC & \\
\hline Vgf-F & AAGGATGACGGCGTACCAGA & 114 \\
\hline Vgf-R & TGCCTGCAACAGTACCGAG & \\
\hline Per2-F & GAAAGCTGTCACCACCATAGAA & 101 \\
\hline Per2-R & AACTCGCACTTCCTITCAGG & \\
\hline Acads-F & TGGCGACGGTTACACACTG & 231 \\
\hline Acads- $R$ & GTAGGCCAGGTAATCCAAGCC & \\
\hline Fabp3-F & ACCTGGAAGCTAGTGGACAG & 106 \\
\hline Fabp3-R & TGATGGTAGTAGGCTTGGTCAT & \\
\hline Prkab2-F & АССАTСTCTATGCACTGTCCA & 86 \\
\hline Prkab2-R & CAGCGTGGTGACATACTTCTT & \\
\hline Dgat1-F & TCCGTCCAGGGTGGTAGTG & 199 \\
\hline Dgat1-R & TGAACAAAGAATCTTGCAGACGA & \\
\hline Hdac6-F & TCCACCGGCCAAGATTCTTC & 109 \\
\hline Hdac6-R & CAGCACACTTCTTTCCACCAC & \\
\hline Egr2-F & GCCAAGGCCGTAGACAAAATC & 154 \\
\hline Egr2-R & CCACTCCGTTCATCTGGTCA & \\
\hline Apmap-F & СCTTGCCATTCCСCTACTTGG & 116 \\
\hline Apmap-R & ACTTCGTATTTGGATGCAGAACA & \\
\hline FABP4-F & AAGGTGAAGAGCATCATAACCCT & 133 \\
\hline FABP4-R & TCACGCCTTTCATAACACATTCC & \\
\hline PPARG $\gamma-F$ & TCGCTGATGCACTGCCTATG & 103 \\
\hline PPARG $\gamma-R$ & GAGAGGTCCACAGAGCTGATT & \\
\hline$\beta$-actin-F & GGCTGTATTCCCCTCCATCG & 154 \\
\hline$\beta$-actin-R & CCAGTTGGTAACAATGCCATGT & \\
\hline
\end{tabular}

cycle and had adequate access to food and water. All animal care protocols and experiments were reviewed and approved by the Animal Care and Use Committee of the Laboratory Animal Research Center at The Second Xiangya Hospital of Central South University.

\section{Isolation and Culture of BMSCs}

BMSCs were isolated as previously described (Picke et al., 2018). Briefly, the femora and tibiae of four 7-day-old mice were cut and digested with Liberase DL $(26 \mathrm{U} / \mathrm{mL})$ (Roche) in a water bath at $37^{\circ} \mathrm{C}$ for $2 \mathrm{~h}$. The cell suspension was centrifugated at $1,000 \mathrm{rpm}$ for $5 \mathrm{~min}$ at $4^{\circ} \mathrm{C}$, resuspended in $1 \mathrm{~mL}$ of $\alpha$-MEM containing $1 \%$ penicillin/streptomycin and $10 \%$ FBS, and then cultured in a $10-\mathrm{cm}$ culture dish. The medium was replaced every other day and $\mathrm{CD} 11 \mathrm{~b}^{+}$cells were cleared using anti-CD11b antibody-coated magnetic beads.

\section{Osteogenic Differentiation and Mineralization Assay}

Isolated BMSCs were digested with $0.25 \%$ trypsin and diluted to $1 \times 10^{7}$ cells $/ \mathrm{mL}$. Then, $200 \mu \mathrm{L}$ of the cell suspension was plated in 6-well plates at a density of $2 \times 10^{6}$ cells/well. At $80 \%$ confluence, the medium was replaced with osteogenic induction medium containing 10\% FBS, $1 \%$ penicillin/streptomycin, $0.1 \mathrm{mM}$ dexamethasone, $10 \mathrm{mM}$ $\beta$-glycerol phosphate, and $50 \mathrm{mM}$ ascorbate. The osteogenic induction medium was renewed every 3 days for 21 days. The cells were subsequently fixed in $4 \%$ paraformaldehyde and stained with 2\% Alizarin Red S (Sigma-Aldrich). The Alizarin Red S was dissolved in cetylpyridinium chloride solution and quantified by spectrophotometry at $540 \mathrm{~nm}$.

\section{Adipogenic Differentiation Assay}

Isolated BMSCs were plated in 6-well plates at $2.5 \times 10^{6}$ cells/well in adipogenic differentiation medium containing $10 \%$ FBS, $1 \%$ penicillin/streptomycin, $0.5 \mathrm{mM}$ 3-isobutyl-1methylxanthine, $1 \mu \mathrm{M}$ dexamethasone, and $5 \mu \mathrm{g} / \mathrm{mL}$ insulin. The adipogenic induction medium was renewed every 3 days for 14 days. The cells were then fixed in $4 \%$ paraformaldehyde and stained with Oil Red solution (Sigma-Aldrich). The dye was solubilized in isopropanol and the absorption at $540 \mathrm{~nm}$ was measured using a BioTek Epoch microplate spectrophotometer (BioTek Instruments).

\section{Enzyme-Linked Immunosorbent Assay (ELISA)}

Bone marrow was separated, centrifuged at $1,000 \mathrm{rpm}$ for $10 \mathrm{~min}$, and then the supernatant was transferred to a new centrifuge tube. ELISA was performed using a CGPR (rat, mouse) EIA-Kit (K-01509, Phoenix Pharmaceuticals) according to the manufacturer's instructions.

\section{Quantitative Real-Time PCR Analysis}

Total RNA $(1 \mu \mathrm{g})$ isolated from CGRP-treated BMSCs was treated with gDNA Eraser to remove residual genomic DNA and then reverse-transcribed into cDNA using the PrimeScript RT reagent Kit (Takara, Japan). Real-time PCR analysis was performed with SYBR Green (Takara, Japan) in an Applied Biosystems QuantStudio 3 Real-Time PCR System (Applied Biosystems). The amplification reactions were performed in a 96well plate and consisted of 40 cycles of $95^{\circ} \mathrm{C}$ for $5 \mathrm{~s}$ and $60^{\circ} \mathrm{C}$ for $30 \mathrm{~s}$. The relative transcript levels of target genes were quantified using the $2^{-\Delta \Delta C t}$ method with beta-actin serving as the internal control. The primer sequences are listed in Table 1.

\section{Micro-CT Analysis}

Micro-computed tomography (micro-CT) analysis was performed as previously reported (Li et al., 2015; Yang et al., 2019). The femora of mice from both the CGRP treatment group and the control group were isolated, fixed in $4 \%$ formaldehyde for $24 \mathrm{~h}$, and then scanned by X-ray microtomography (Skyscan 1172, Bruker) at a pixel size of $13.98 \mu \mathrm{m}$. For the distal femur, the region-of-interest (ROI) was defined from 0.215 to $1.72 \mathrm{~mm}$ below the growth plate. The bone volume as a fraction of total bone volume (BV/TV), trabecular thickness (Tb. Th), trabecular number $(\mathrm{Tb} . \mathrm{N})$, and trabecular separation ( $\mathrm{Tb}$. Sp) were measured. 


\section{Immunohistochemistry and Tartrate-Resistant Acid Phosphatase (TRAP) Staining}

The femora were decalcified with 0.5 M EDTA for 1-2 weeks and then embedded in paraffin. The paraffin-embedded femora were sectioned $(4 \mu \mathrm{m})$ using a RM2135 rotary microtome (Leica Geosystems). Sections were roasted at $60^{\circ} \mathrm{C}$ in an oven for $2 \mathrm{~h}$, dewaxed with dimethyl benzene, dehydrated with alcohol, and treated with an antigen retrieval solution. The sections were subsequently washed with $1 \times$ TTBS, blocked with $5 \%$ goat serum, and incubated with an anti-osteocalcin primary antibody (diluted 1:500; Cat\# M041, Takara) overnight at $4^{\circ} \mathrm{C}$. The next day, the sections were washed with $1 \times$ TTBS, incubated with biotinylated secondary antibody (anti-mouse,1:200; Cat\# PV9000, Beijing Zhongshan Jinqiao Biotechnology Co. Ltd.) for $1 \mathrm{~h}$, washed with $1 \times$ TTBS, and counterstained with hematoxylin (Sigma-Aldrich) for immunohistochemical analysis. An inverted fluorescence microscope was used for imaging. For TRAP staining, an Osteoclast Staining Kit (Sigma-Aldrich) was used according to the manufacturer's instructions. The number of osteoblasts on the bone surface and osteoclast number per bone perimeter were measured in the femora.

\section{$\beta$-Galactosidase Staining}

BMSCs were washed with $1 \times$ PBS and fixed in $4 \%$ formaldehyde for $30 \mathrm{~min}$. Cell senescence was assessed using a $\beta$-Galactosidase Staining Kit (Cell Signaling Technology, 9860) according to the manufacturer's instructions. The percentage of senescent cells was determined using ImageJ software.

\section{Statistical Analysis}

Data were analyzed by unpaired, two-tailed, Student's $t$-tests or one-way or two-way analysis of variance (ANOVA) followed by Bonferroni's post-test using GraphPad Prism 7.0 software. All data are presented as means \pm SEM. A $p$-value $<0.05$ was considered statistically significant.

\section{RESULTS}

\section{CGRP Levels Were Decreased in the Bone Marrow Supernatant of Mice During Aging}

CGRP is a 37-residue neuropeptide primarily expressed in the central and peripheral nervous systems (Emeson et al., 1989, 1992). That CGRP plays a vital role in bone metabolism is supported by evidence showing that the lack of CGRP results in reduced bone formation and impaired bone regeneration in mice (Schinke et al., 2004; Appelt et al., 2020). To assess the expression of Calca (encoding $\alpha$-CGRP) in bone tissue during aging, we conducted RT-qPCR analysis on total RNA extracted from the bone tissue of mice at 3, 6, 9, 12, 15, 18, 21 , and 24 months of age ( $n=5$ per age group). We found that the Calca level was significantly decreased during aging (Figure 1A). CGRP is thought to be a secreted neuropeptide that is released from sensory nerve endings (Tsujikawa et al., 2007). To assess the CGRP levels in bone marrow, we collected bone marrow supernatant from male C57BL/6JN mice aged 3, 12, and 24 months ( $n=5$ per age group) and measured CGRP levels by ELISA. As shown in Figure 1B, CGRP levels were lower in aged mice than in young mice. Given the vital role of CGRP in bone metabolism (Irie et al., 2002; Schinke et al., 2004; Appelt et al., 2020) and that CGRP has been reported to stimulate the proliferation and osteogenic differentiation of rat-derived BMSCs (Liang et al., 2015), we subsequently hypothesized that CGRP may be involved in regulating BMSC functions during the aging process in mice.

\section{CGRP Treatment Promoted BMSC Osteogenic Differentiation and Reduced BMSC Senescence}

To evaluate the effect of CGRP on the osteogenic differentiation potential of BMSCs, we isolated BMSCs from femoral and
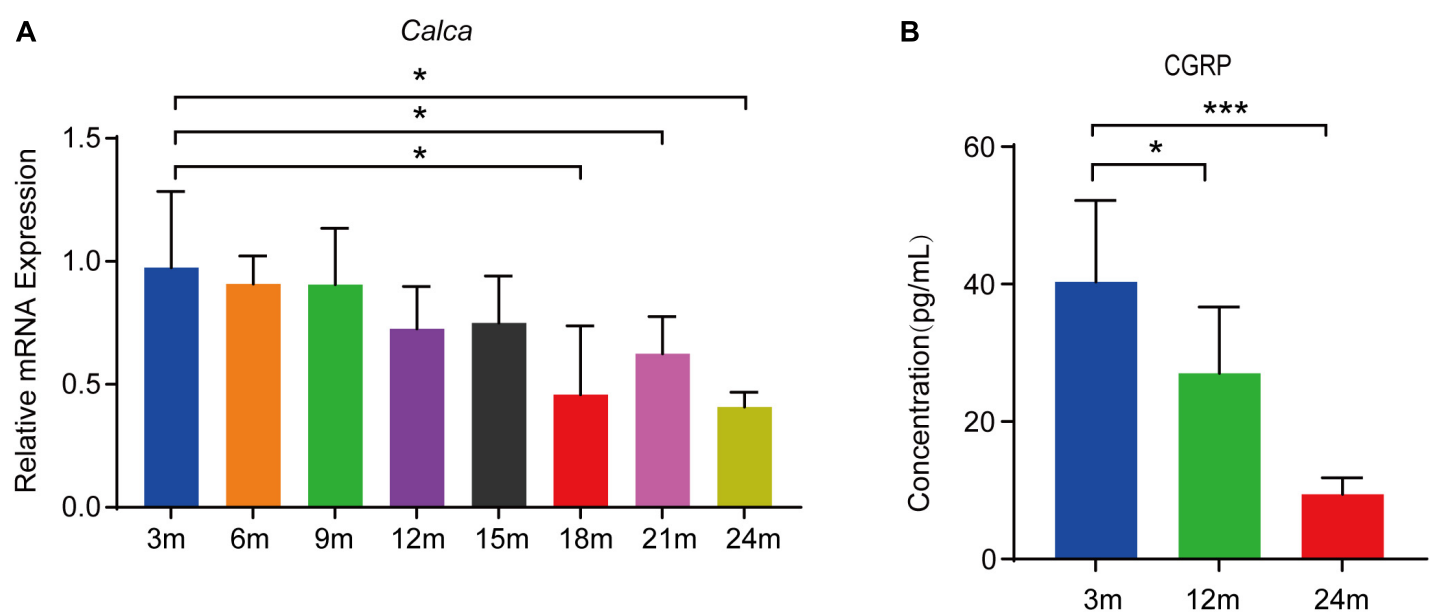

FIGURE 1 | CGRP levels were decreased in the bone marrow supernatant of mice during aging. (A) RT-qPCR analysis of the mRNA level of Calca in bone tissue of mice at $3,6,9,12,15,18,21$, and 24 months of age ( $n=5$ per age group). (B) The relative levels of CGRP in bone marrow supernatant were measured by ELISA. ${ }^{\star} P<0.05,{ }^{\star \star \star} P<0.001$ 

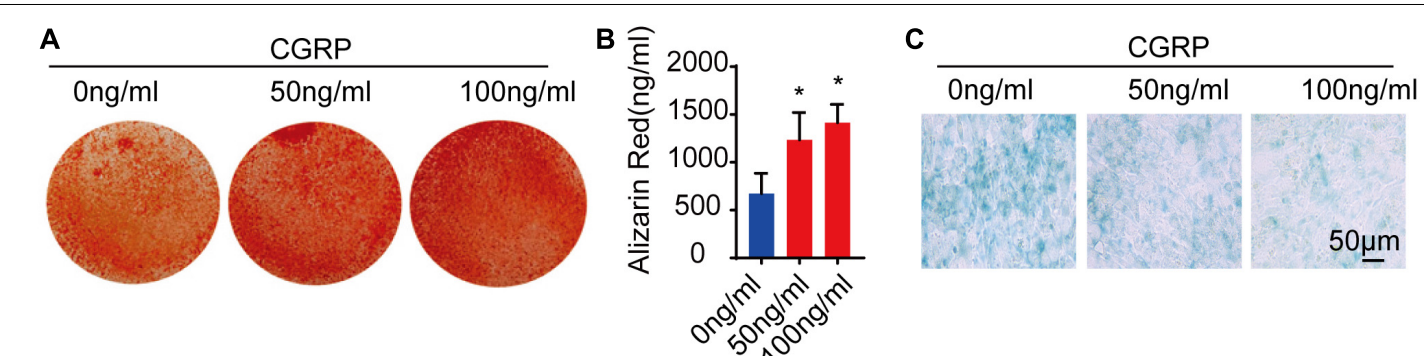

E

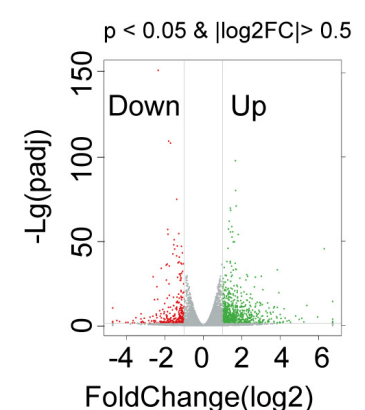

$F$

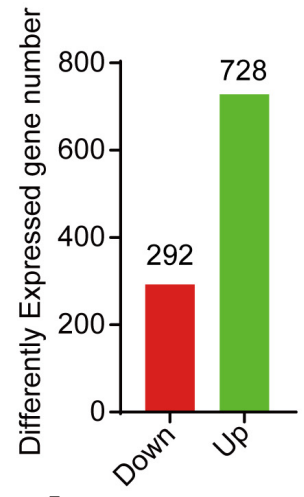

G

\section{ECM-receptor interaction} PPAR signaling pathway Focal adhesion cAMP signaling pathway MAPK signaling pathway Rap1 signaling pathway Hypertrophic cardiomyopathy ( $\mathrm{HCM}$ )

Regulation of lipolysis in adipocyte PI3K-Akt signaling pathway Aldosterone synthesis and secretion

H
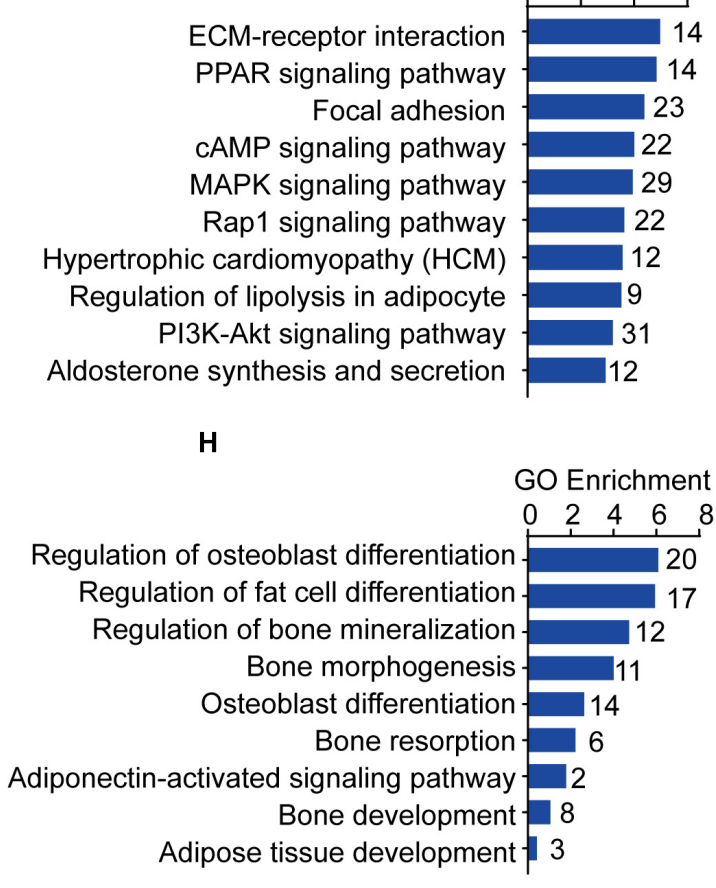

Adipose tissue development 13
KEGG Enrichment $\quad \mathrm{I} \quad \frac{\text { Control }}{123} \quad \frac{\text { CGRP }}{123}$

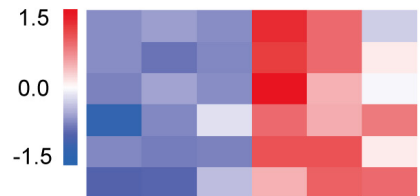

Gdpd2

lgf1

Fgf9

Wnt10b

Gli2

Rspo2

Jag1

Sox2

Igfbp3

$\lg 2$

Bmp8a

Bmp4

Id4

Bmp6

Acvr2a

Pth1r

Lrp5

Hdac5

Hey1

Dlk1

Tmem119

Fam20c

Gja1

Tgfbr3

Col1a1

Ift80
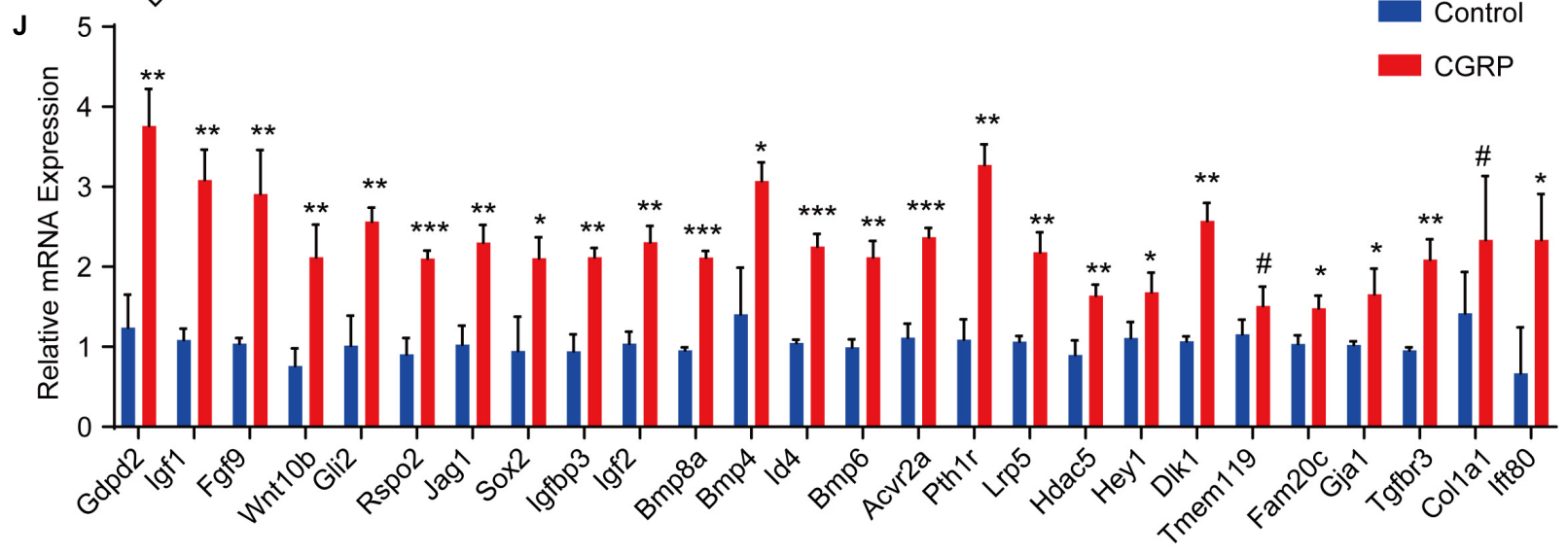

FIGURE 2 | CGRP induced the osteogenic differentiation of bone marrow-derived stem cells (BMSCs) and reduced BMSC senescence. (A) Representative images of Alizarin Red staining and (B) quantitative analysis of matrix mineralization in BMSCs treated with or without CGRP. (C) Representative images of beta-galactosidase staining and (D) quantitative analysis of the percentage of senescent cells in BMSCs treated with or without CGRP. (E) Volcano map and (F) histogram of differentially expressed genes between the CGRP treatment and control groups. Red spots represent downregulated genes and green spots represent upregulated genes. (G) Enrichment of differentially expressed genes was tested using Kyoto Encyclopedia of Genes and Genomes (KEGG) pathway analysis and (H) Gene Ontology (GO) analysis. (I) A heatmap of the mRNA-seq profile of BMSCs treated with or without CGRP. Fold-change $\geq 2.0$. (J) RT-qPCR analysis of gene expression levels in BMSCs treated with or without CGRP. Scale bar, $50 \mu \mathrm{m}$. Data are presented as means $\pm \mathrm{SEM}$. ${ }^{\star} P<0.05,{ }^{\star \star} P<0.01$, ${ }^{* \star} P<0.001$. 
tibial bone marrow of mice and cultured them first in a complete medium, and then in an osteogenesis induction medium containing CGRP at 0,50 , or $100 \mathrm{ng} / \mathrm{mL}$. Alizarin Red staining and quantitative analysis of calcium content indicated that the ability of BMSCs to form mineralized nodules was enhanced in the CGRP treatment group compared with that in the control group (Figures 2A,B). A similar result was obtained for BMSCs transfected with a CGRP expression plasmid (Supplementary Figures 1A,B). In mice, the capacity of BMSCs to differentiate into osteoblasts is known to decrease with age. Consequently, we next measured the effect of CGRP on BMSC senescence by $\beta$-galactosidase staining. As expected, the percentage of senescent cells ( $\beta$-galactosidase $\left.{ }^{+}\right)$was significantly lower in the CGRP treatment group than in the control group (Figures 2C,D). To determine the mechanism underlying the effect of CGRP on osteogenic differentiation of BMSCs and BMSC senescence, we performed RNA-seq to identify differences in mRNA expression levels between the CGRP treatment group and the control group. A total of 1,020 differentially expressed mRNAs ( $\log 2$ fold-change $\geq 2$ ) were identified (Figures $2 \mathbf{E}, \mathbf{F}$ ). Using Kyoto Encyclopedia of Genes and Genomes (KEGG) pathway and Gene Ontology (GO) enrichment analyses of the differentially expressed genes (Figures 2G,H), we identified several biological processes involved in osteogenic and fat cell differentiation (Figure 2H). Analysis of a heatmap depicting the differentially expressed genes involved in the regulation of osteoblast differentiation demonstrated that almost all of these genes, including Gdpd2, Igf1, Fgf9, Wnt10b, Gli2, Rspo2,
Jag1, Sox2, Igfbp3, Igf2, Bmp4, Bmp6, Bmp8a, Id4, Acvr2a, Pth1r, Lrp5, Hdac5, Hey1, Dlk1, Tmem119, Fam20c, Gja1, Tgfbr3, Col1a1, and Ift80, were markedly upregulated in the CGRP treatment group compared with that in the control group (Figure 2I). The result of the RNA-seq was further confirmed by RT-qPCR analysis (Figure 2J). Combined, the results showed that CGRP treatment dose-dependently increased the osteogenic differentiation potential of BMSCs and reduced BMSC senescence.

\section{CGRP Inhibited the Adipogenic Differentiation of BMSCs}

BMSCs are multipotent stem cells capable of differentiating into multiple lineages, including osteoblasts and adipocytes (Pittenger et al., 1999; James, 2013). The differentiation potential of BMSCs is influenced by multiple factors, such as injury. Given our above results showing that CGRP can induce the osteogenic differentiation of BMSCs and reduce BMSC senescence, we then tested whether CGRP treatment could also affect the adipogenic differentiation capacity of BMSCs. To evaluate this possibility in vitro, BMSCs were cultured in an adipogenesis induction medium containing CGRP at 0,50 , or $100 \mathrm{ng} / \mathrm{mL}$. Oil Red $\mathrm{O}$ staining results showed that there were fewer lipid droplets and their size was reduced in CGRP-treated BMSCs compared with that in control BMSCs (Figures 3A,B). We obtained a similar result in BMSCs transfected with a CGRP expression plasmid (Supplementary Figures 1C,D). Next, we
A
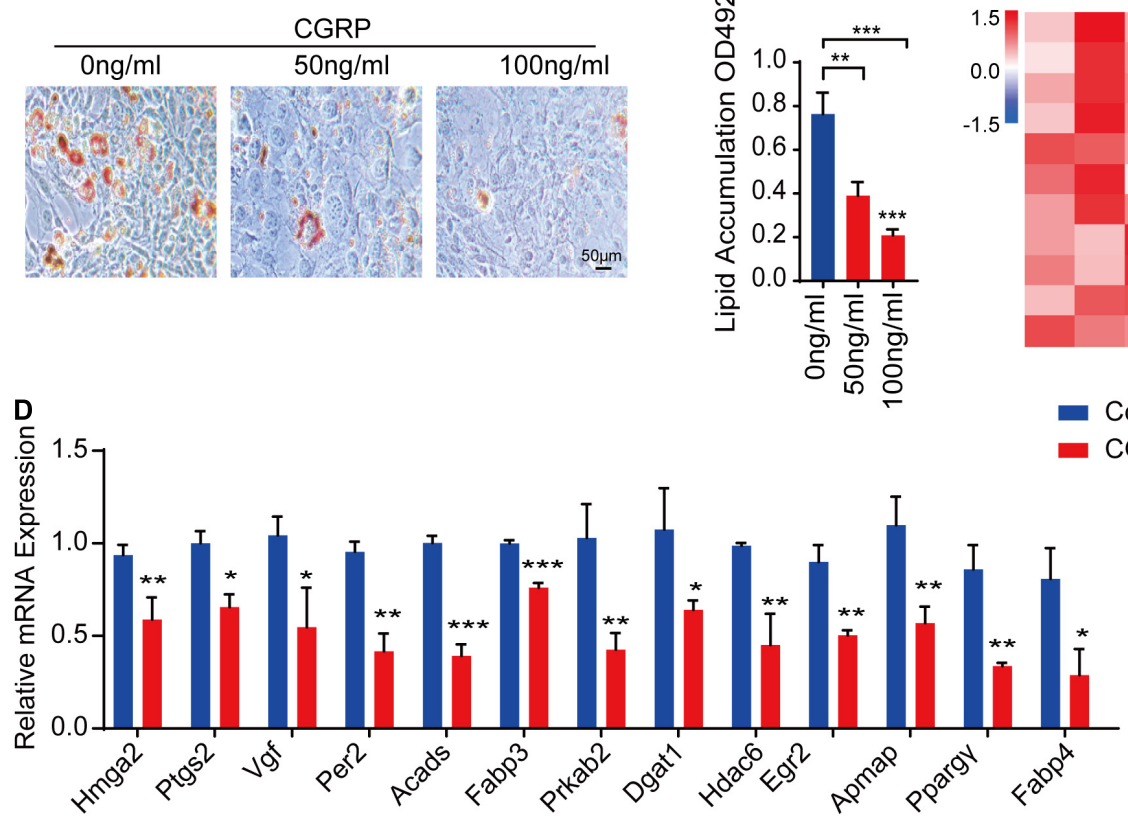

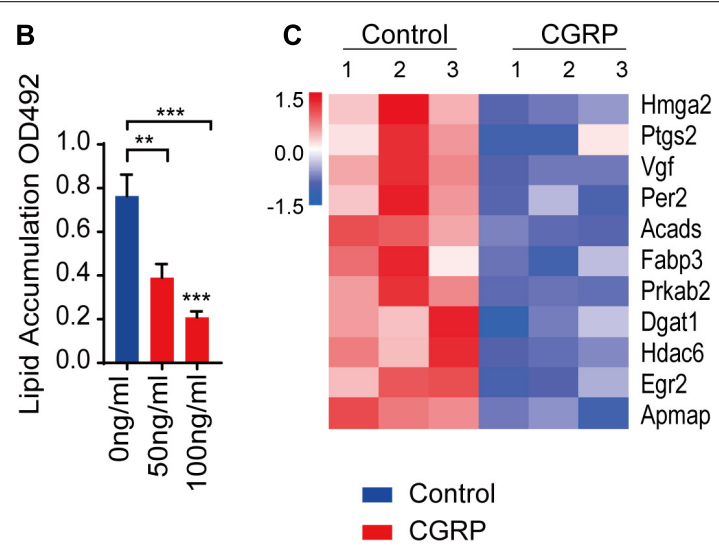

FIGURE 3 | CGRP inhibited the adipogenic differentiation of bone marrow-derived stem cells (BMSCs). (A) Representative images of Oil Red O staining and (B) quantitative analysis of lipid droplet formation in BMSCs treated with or without CGRP. (C) A heatmap of the mRNA-seq profile of BMSCs treated with or without CGRP. Fold change $\geq 2$.0. (D) RT-qPCR analysis of gene expression levels in BMSCs treated with or without CGRP. Scale bar, $50 \mu \mathrm{m}$. Data are presented as means \pm SEM. ${ }^{\star} P<0.05,{ }^{\star \star} P<0.01,{ }^{\star \star *} P<0.001$. 
identified genes involved in promoting adipogenesis that were differentially expressed between the CGRP treatment group and the control group. Heatmap analysis showed that, compared with control BMSCs, the expression of Hmga2, Ptgs2, Vgf, Per2, Acads, Fabp3, Prkab2, Dgat1, Hdac6, Egr2, and Apmap was markedly downregulated in those treated with CGRP (Figure 3C). RT-qPCR analysis further confirmed the RNA-seq results (Figure 3D). These data indicated that CGRP treatment downregulated the expression of adipogenesis-related genes and inhibited the adipogenic differentiation capacity of BMSCs.

\section{CGRP Treatment Promoted Bone Formation in Aged Mice}

To evaluate whether CGRP could promote bone formation in aged mice in vivo, 12-month-old male C57BL/6JN mice $(n=5)$ were administered CGRP $(10 \mathrm{mg} / \mathrm{kg})$ or $1 \times \mathrm{PBS}$ via tail vein injection three times weekly (Figure 4A). After 1 month, the bone phenotype of the mice in both groups was analyzed. The results showed that bone mass, BV, Tb. Th, and Tb. $\mathrm{N}$ were markedly higher, and the Tb. Sp lower, in mice treated with CGRP when compared with those treated with
PBS (Figures 4B-F). Hematoxylin and eosin (H\&E) staining results showed that, compared with PBS-treated mice, those treated with CGRP had fewer adipocytes, and the area occupied by them was smaller (Figures $\mathbf{4 G}, \mathbf{H}$ ). Moreover, the number of osteocalcin ${ }^{+}$osteoblasts on the trabecular surface was also higher in mice treated with CGRP compared with that of the control group (Figures 4I,J). These results suggested that CGRP treatment induced osteoblast differentiation and promoted bone formation in aged mice.

\section{CGRP Treatment Promoted Bone Formation in OVX Mice}

The OVX rodent model is well-established as a means for investigating osteoporosis and osteoporotic therapies (Mathavan et al., 2015). Here, to test the effect of CGRP on bone formation in OVX mice, we generated a model of postmenopausal osteoporosis via bilateral ovarian resection in 2-month-old female C57BL/6JN mice ( $n=12$ /group). One month after the operation, CGRP $(10 \mathrm{mg} / \mathrm{kg})$ or $1 \times$ PBS $(10 \mathrm{mg} / \mathrm{kg})$ was administered into mice of the OVX and sham operation groups via tail vein injection and ovarian injections three

A

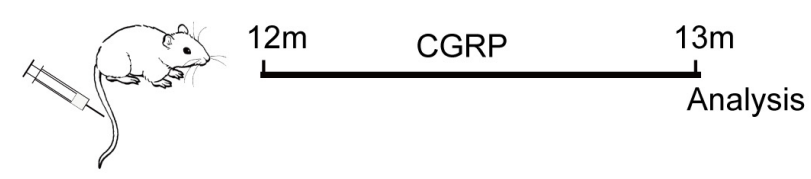

B
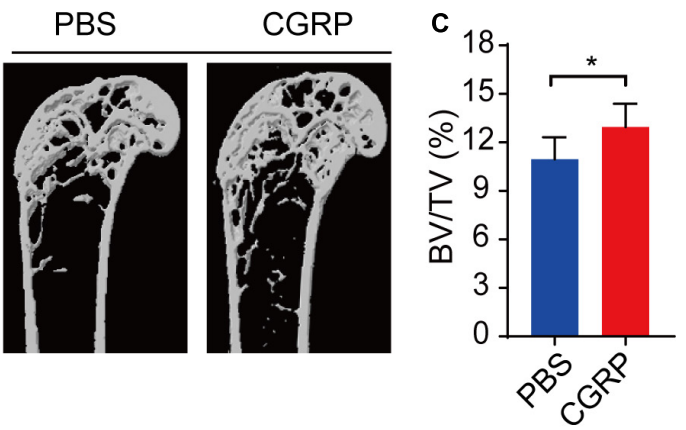

D
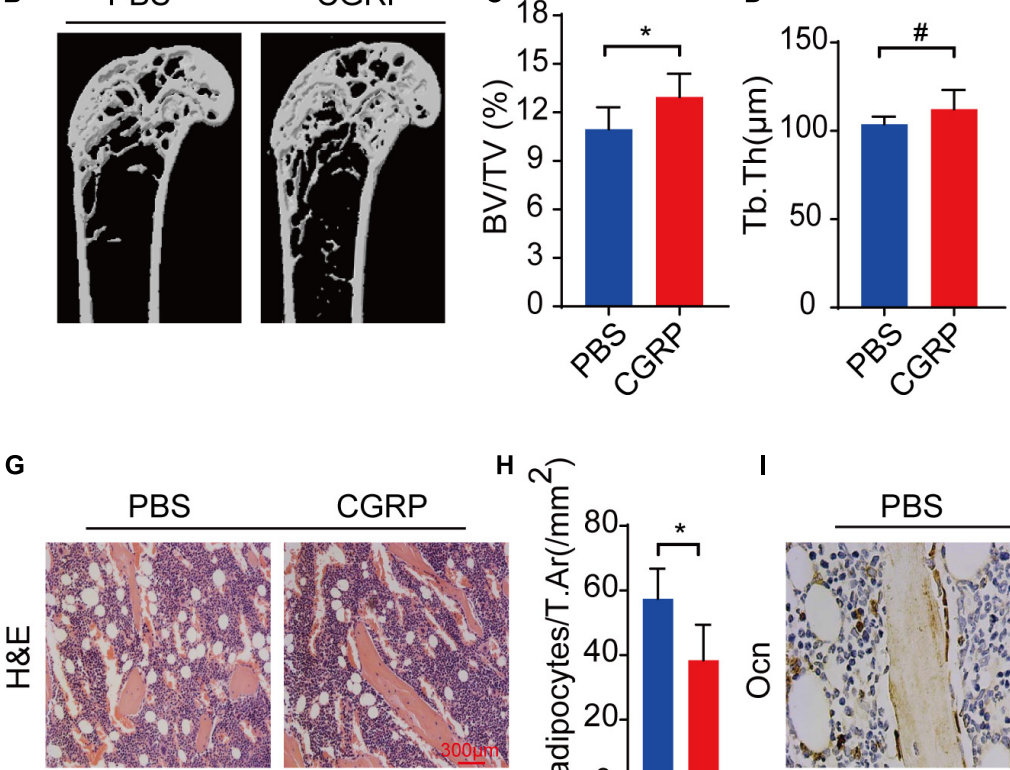

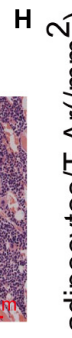

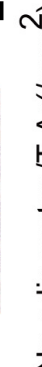

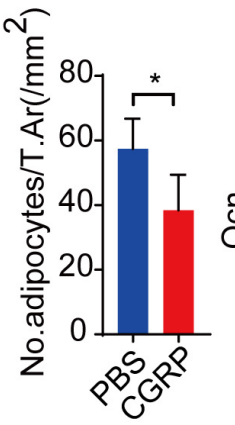

I

E
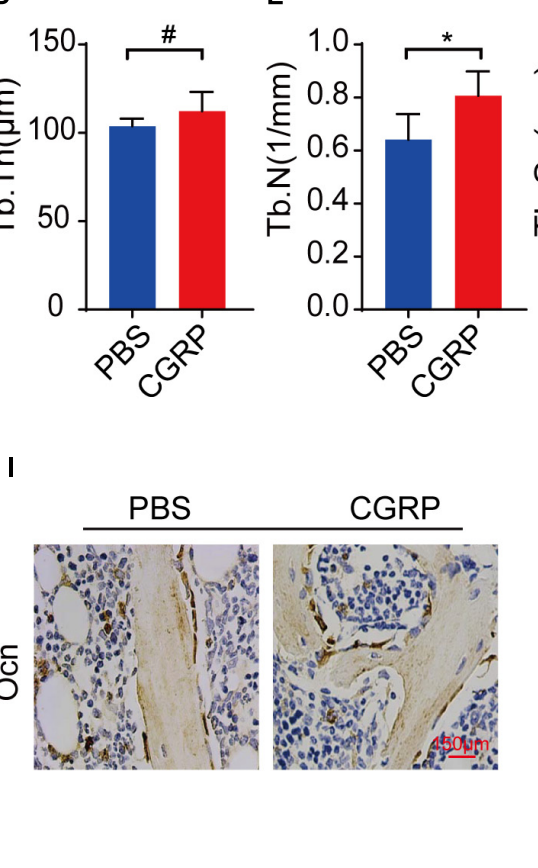

$\mathbf{F}$
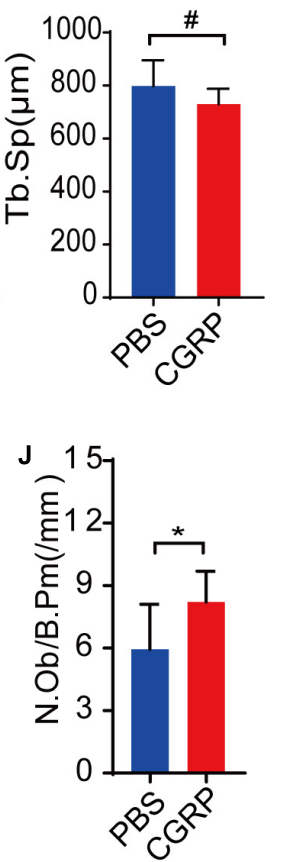

FIGURE 4 | CGRP treatment promoted bone formation in aged mice. (A) A schematic representation of the injection protocol (CGRP or $1 \times$ PBS via the tail vein) in aged mice. (B) Representative micro-computed tomographs $(n=6 /$ group) and (C-F) quantitative analysis of bone volume as a fraction of total bone volume (BV/TV), trabecular thickness (Tb. Th), trabecular number (Tb. N), and trabecular separation (Tb. Sp) of femora from CGRP-treated and control mice. (G) Representative images of hematoxylin and eosin staining and $\mathbf{( H )}$ quantitative analysis of the number and area of adipocytes in the bone marrow of CGRP-treated and control mice. (I) Representative images of osteocalcin (OCN) staining and (J) quantification of osteoblast bone surface density (N.Ob/B.Pm) in the femora of CGRP-treated and control mice. Scale bars, $150 \mu \mathrm{m}$. Data are presented as means $\pm \mathrm{SEM}$. ${ }^{*} P<0.05$. \# means no statistical significance. 


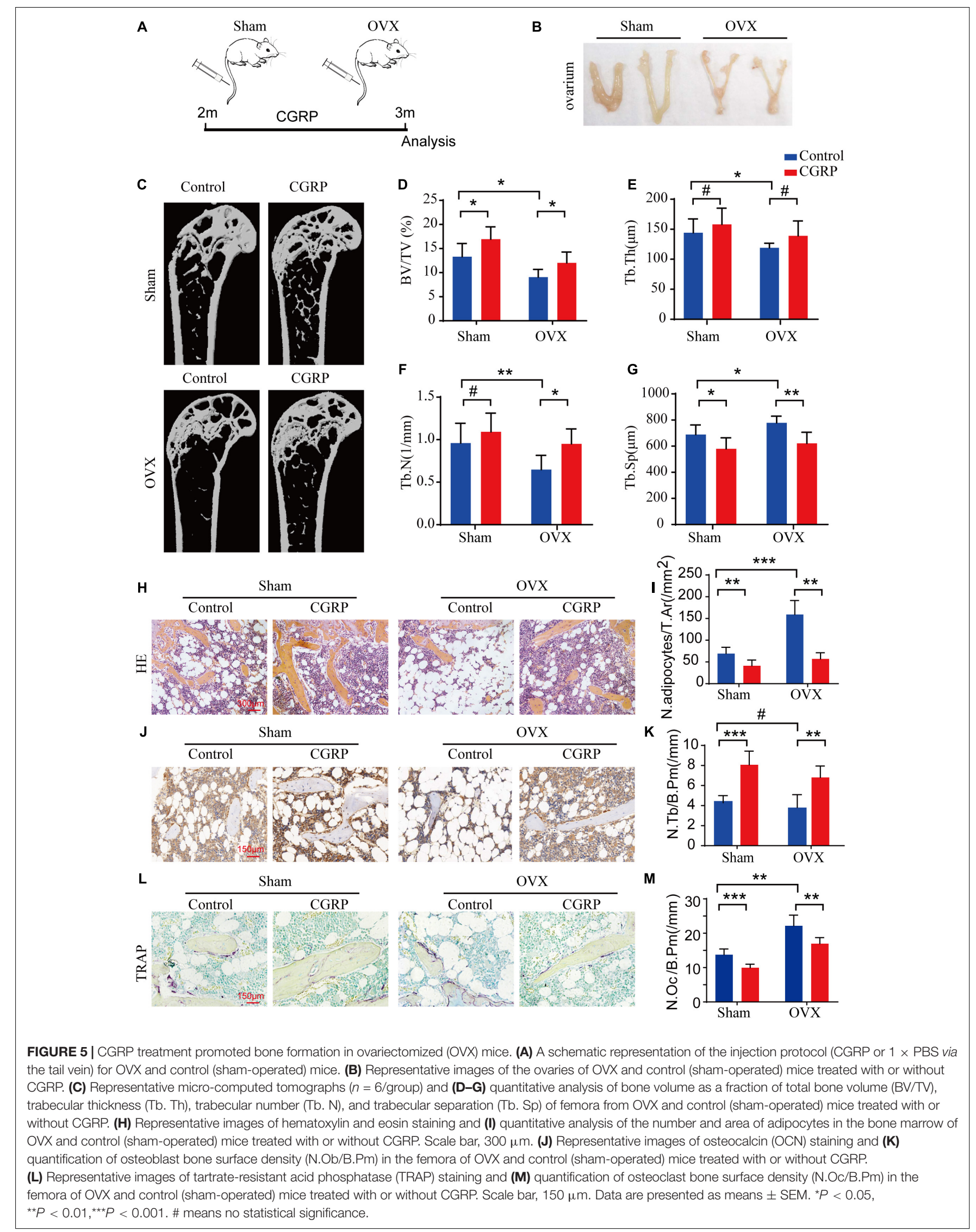


times weekly (Figures 5A,B). We found that the BV and $\mathrm{Tb}$. Th were markedly reduced in the OVX group compared with those in the sham operation group, indicating that the model of postmenopausal osteoporosis had been successfully generated (Figures 5C-G). Moreover, bone mass, BV, Tb. Th, and $\mathrm{Tb}$. $\mathrm{N}$ were markedly increased, while the $\mathrm{Tb}$. Sp. was reduced, in CGRP-treated mice from both the OVX and sham operation groups compared with that in PBS-treated mice from both groups (Figure 5C-G). Additionally, when compared with control mice, CGRP-treated mice from the OVX and sham operation groups displayed fewer adipocytes and smaller adipocyte-containing areas in the bone marrow (Figures $\mathbf{5 H}, \mathbf{I}$ ), as well as greater numbers of osteocalcin ${ }^{+}$osteoblasts and alkaline phosphatase ${ }^{+}$osteoprogenitors on the bone surfaces (Figures 5J,K). In contrast, CGRP-treated mice from the OVX and sham operation groups had fewer $\mathrm{TRAP}^{+}$osteoclasts on the bone surfaces (Figures $\mathbf{5 L}, \mathbf{M}$ ), which was consistent with the results of previous in vitro studies (Wang et al., 2010). Taken together, these results suggested that CGRP can promote bone formation in both aged and osteoporotic (OVX) mice, and suggest a potential approach for the treatment of agerelated osteoporosis.

\section{DISCUSSION}

Osteoporosis is a chronic, age-related disease that seriously affects the quality of life of both the elderly and postmenopausal women (Rachner et al., 2011). Owing to the aging of the world's population, it is increasingly important to understand the role of neuropeptides and their receptors in the aging process (Naot and Cornish, 2008). In the elderly, BMSCs have a greater capacity to differentiate along adipocytic lineages than along osteoblastic lineages, leading to the gradual accumulation of fat and the loss of bone (Bartel, 2004). Here, we demonstrated that CGRP is involved in the shift in BMSC cell lineage commitment, which leads to increased osteogenic differentiation and reduced adipogenic differentiation of BMSCs. Furthermore, we demonstrated for the first time that systemic CGRP administration can reduce fat accumulation, as well as promote bone formation, in both aged and OVX mice, likely by acting on BMSCs.

CGRP can reportedly regulate BMSC lineage commitment (Villa et al., 2003; Wang et al., 2010; Naot et al., 2019). In addition, several studies have shown that CGRP levels are influenced by age, and that these age-related changes can affect osteogenesis (Imai and Matsusue, 2002; Villa et al., 2003; Niedermair et al., 2020). These results are consistent with those reported here. We found that the level of CGRP in bone marrow supernatants was inversely proportional to age. Furthermore, CGRP treatment enhanced the ability of BMSCs to form mineralized nodules and significantly reduced the percentage of senescent BMSCs. Given the interaction between osteogenesis and adipogenesis, we further examined the role of CGRP in adipogenic differentiation, and report for the first time that CGRP can inhibit the adipogenic differentiation of BMSCs. These results indicated that CGRP regulates BMSC lineage commitment during aging and contributes to agerelated bone formation.

It has recently been suggested that CGRP is a key neuropeptide in bone metabolism. Niedermair et al. (2020) demonstrated that CGRP regulates the bone remodeling properties of osteoblasts and osteoclasts in an age-dependent manner. Further, Mi et al. (2021) reported that CGRP can increase the endothelial progenitor cell population in the endothelial differentiation of BMSCs in vitro, thereby promoting bone regeneration in a rat model of distraction osteogenesis. In addition, it has been shown that CGRP can enhance BMP2 signal transduction, the expression of related osteogenic genes, and mineralization in vitro (Tuzmen and Campbell, 2018). He et al. (2016) reported that CGRP can maintain bone mass by stimulating osteoblast differentiation and inhibiting RANKLinduced osteoclastogenesis and bone resorption. CGRP has also been indicated to serve as a protective mechanism against particle-induced osteolysis (Kauther et al., 2011). However, to date, no work has reported on the role of CGRP in the regulation of BMSC function. In the present study, we defined a new mechanism through which CGRP regulates the BMSC switch in the bone. We further identified biological processes involved in both osteogenic and adipocyte differentiation and found that CGRP treatment led to a significant upregulation of the expression of almost all osteogenesis-related genes. Furthermore, based on the decrease in the expression level of adipogenesis-related genes, we reasoned that CGRP might suppress adipogenesis.

These results suggested that CGRP influences the direction of BMSC differentiation by regulating the expression of related genes, thereby providing a neuropeptide-mediated link to the age-related transition between osteoblast and adipocyte differentiation. During the aging process, the level of CGRP and the expression of osteogenic-related genes in the bone marrow decreases, whereas that of lipid-related genes increases. Consequently, BMSCs tend to differentiate into adipocytes, leading to a reduction in the number of osteoblasts and an increase in that of adipocytes, resulting in age-related bone loss. Here, we identified a new mechanism through which CGRP regulates the differentiation of BMSCs during aging. Relatively few studies have investigated the role of CGRP in bone metabolism in vivo. Here, via the delivery of CGRP to BMSCs by tail vein injection, we confirmed in vivo that CGRP can promote the osteogenic differentiation of BMSCs and inhibit fat accumulation in the bone marrow. The results of bone histomorphometry in the CGRP-treated group were significantly better than those in the control group in both aged and OVX mice. In vitro and in vivo experiments both confirmed that CGRP can promote the osteogenic differentiation and inhibit the adipogenic differentiation of BMSCs.

With the aging of the world's population, age-related osteoporosis has become a serious public health issue (Curtis and Safford, 2012). However, most drugs currently used to treat osteoporosis are aimed at inhibiting bone resorption without promoting bone formation, and most are accompanied by severe side effects ( $\mathrm{Hu}$ et al., 2020). In this study, we identified a new neuropeptide that may serve as potential therapeutic target for 
the treatment of osteoporosis. To date, CGRP has been applied in the treatment of several diseases, such as migraine, diabetes, and liver damage, as well as for cardioprotection (Kroeger et al., 2009; Yuan et al., 2017; Guo et al., 2018, 2020), suggesting that CGRP can be used safely and effectively in the treatment of age-related osteoporosis.

\section{CONCLUSION}

In conclusion, our findings support that the age-related changes in CGRP levels regulate BMSC differentiation. Our results revealed a novel mechanism underlying age-related bone loss and provide a potential therapeutic strategy to treat agerelated osteoporosis.

\section{DATA AVAILABILITY STATEMENT}

The raw data supporting the conclusions of this article will be made available by the authors, without undue reservation.

\section{ETHICS STATEMENT}

All animal care protocols and experiments were reviewed and approved by the Animal Care and Use Committee of the Laboratory Animal Research Center at the Second Xiangya

\section{REFERENCES}

Amara, S. G., Jonas, V., Rosenfeld, M. G., Ong, E. S., and Evans, R. M. (1982). Alternative RNA processing in calcitonin gene expression generates mRNAs encoding different polypeptide products. Nature 298, 240-244. doi: 10.1038/ 298240a0

Appelt, J., Baranowsky, A., Jahn, D., Yorgan, T., Kohli, P., Otto, E., et al. (2020). The neuropeptide calcitonin gene-related peptide alpha is essential for bone healing. EBioMedicine 59:102970. doi: 10.1016/j.ebiom.2020.102970

Bartel, D. P. (2004). MicroRNAs: genomics, biogenesis, mechanism, and function. Cell 116, 281-297. doi: 10.1016/s0092-8674(04)00045-5

Bjurholm, A., Kreicbergs, A., Brodin, E., and Schultzberg, M. (1988). Substance Pand CGRP-immunoreactive nerves in bone. Peptides 9, 165-171. doi: 10.1016/ 0196-9781(88)90023-x

Chattergoon, N. N., D’Souza, F. M., Deng, W., Chen, H., Hyman, A. L., Kadowitz, P. J., et al. (2005). Antiproliferative effects of calcitonin gene-related peptide in aortic and pulmonary artery smooth muscle cells. Am. J. Physiol. Lung Cell Mol. Physiol. 288, L202-L211. doi: 10.1152/ajplung.00064.2004

Chen, X., Zhi, X., Wang, J., and Su, J. (2018). RANKL signaling in bone marrow mesenchymal stem cells negatively regulates osteoblastic bone formation. Bone Res. 6:34. doi: 10.1038/s41413-018-0035-6

Childs, B. G., Durik, M., Baker, D. J., and van Deursen, J. M. (2015). Cellular senescence in aging and age-related disease: from mechanisms to therapy. Nat. Med. 21, 1424-1435. doi: 10.1038/nm.4000

Curtis, J. R., and Safford, M. M. (2012). Management of osteoporosis among the elderly with other chronic medical conditions. Drugs Aging 29, 549-564. doi: 10.2165/11599620-000000000-00000

Emeson, R. B., Hedjran, F., Yeakley, J. M., Guise, J. W., and Rosenfeld, M. G. (1989). Alternative production of calcitonin and CGRP mRNA is regulated at the calcitonin-specific splice acceptor. Nature 341, 76-80. doi: 10.1038/341076a0

Emeson, R. B., Yeakley, J. M., Hedjran, F., Merillat, N., Lenz, H. J., and Rosenfeld, M. G. (1992). Posttranscriptional regulation of calcitonin/CGRP gene expression. Ann. N. Y. Acad. Sci. 657, 18-35.
Hospital of Central South University. All mice were maintained in the specific pathogen-free facility of the Laboratory Animal Research Center at Central South University.

\section{AUTHOR CONTRIUTIONS}

QL conceived the study. HL and RW drafted the manuscript. $\mathrm{HZ}$ and JW designed the figures. XX and JQ designed the tables. QL and RW revised the manuscript. All the authors were involved in the critical revision of the manuscript and approved the final version.

\section{FUNDING}

This work was supported by the Natural Science Foundation of Hunan Province (2020JJ4799), the China National Key R\&D Program (Nos. 2020YFC2009000 and 2020YFC2009001), and the Natural Science Foundation of Changsha (KQ2007051).

\section{SUPPLEMENTARY MATERIAL}

The Supplementary Material for this article can be found online at: https://www.frontiersin.org/articles/10.3389/fcell.2021. 675503/full\#supplementary-material

Guo, Y., Chen, H., Jiang, Y., Yuan, Y., Zhang, Q., Guo, Q., et al. (2020). CGRP regulates the dysfunction of peri-implant angiogenesis and osseointegration in streptozotocin-induced diabetic rats. Bone 139:115464. doi: 10.1016/j.bone. 2020.115464

Guo, Z., Liu, N., Chen, L., Zhao, X., and Li, M. R. (2018). Independent roles of CGRP in cardioprotection and hemodynamic regulation in ischemic postconditioning. Eur. J. Pharmacol. 828, 18-25. doi: 10.1016/j.ejphar.2018.03. 031

He, H., Chai, J., Zhang, S., Ding, L., Yan, P., Du, W., et al. (2016). CGRP may regulate bone metabolism through stimulating osteoblast differentiation and inhibiting osteoclast formation. Mol. Med. Rep. 13, 3977-3984. doi: 10.3892/ mmr.2016.5023

Hu, Q., Long, C., Wu, D., You, X., Ran, L., Xu, J., et al. (2020). The efficacy and safety of ipriflavone in postmenopausal women with osteopenia or osteoporosis: a systematic review and meta-analysis. Pharmacol. Res. 159:104860. doi: 10. 1016/j.phrs.2020.104860

Idris, A. I., Sophocleous, A., Landao-Bassonga, E., Canals, M., Milligan, G., Baker, D., et al. (2009). Cannabinoid receptor type 1 protects against agerelated osteoporosis by regulating osteoblast and adipocyte differentiation in marrow stromal cells. Cell Metab. 10, 139-147. doi: 10.1016/j.cmet.2 009.07.006

Imai, S., and Matsusue, Y. (2002). Neuronal regulation of bone metabolism and anabolism: calcitonin gene-related peptide-, substance P-, and tyrosine hydroxylase-containing nerves and the bone. Microsc. Res. Tech. 58, 61-69. doi: 10.1002/jemt.10119

Imai, S., Rauvala, H., Konttinen, Y. T., Tokunaga, T., Maeda, T., Hukuda, S., et al. (1997). Efferent targets of osseous CGRP-immunoreactive nerve fiber before and after bone destruction in adjuvant arthritic rat: an ultramorphological study on their terminal-target relations. J. Bone Miner Res. 12, 1018-1027. doi: 10.1359/jbmr.1997.12.7.1018

Irie, K., Hara-Irie, F., Ozawa, H., and Yajima, T. (2002). Calcitonin gene-related peptide (CGRP)-containing nerve fibers in bone tissue and their involvement in bone remodeling. Microsc. Res. Tech. 58, 85-90. doi: 10.1002/jemt.10122 
James, A. W. (2013). Review of signaling pathways governing MSC osteogenic and adipogenic differentiation. Scientifica (Cairo) 2013, 684736. doi: 10.1155/2013/ 684736

Kauther, M. D., Bachmann, H. S., Neuerburg, L., Broecker-Preuss, M., Hilken, G., Grabellus, F., et al. (2011). Calcitonin substitution in calcitonin deficiency reduces particle-induced osteolysis. BMC Musculoskelet Disord. 12:186. doi: 10.1186/1471-2474-12-186

Kroeger, I., Erhardt, A., Abt, D., Fischer, M., Biburger, M., Rau, T., et al. (2009). The neuropeptide calcitonin gene-related peptide (CGRP) prevents inflammatory liver injury in mice. J. Hepatol. 51, 342-353. doi: 10.1016/j.jhep.2009.03.022

Li, C. J., Cheng, P., Liang, M. K., Chen, Y. S., Lu, Q., Wang, J. Y., et al. (2015). MicroRNA-188 regulates age-related switch between osteoblast and adipocyte differentiation. J. Clin. Invest. 125, 1509-1522. doi: 10.1172/JCI77716

Li, H., Liu, P., Xu, S., Li, Y., Dekker, J. D., Li, B., et al. (2017). FOXP1 controls mesenchymal stem cell commitment and senescence during skeletal aging. J. Clin. Invest. 127, 1241-1253. doi: 10.1172/JCI89511

Li, K. C., Chang, Y. H., Yeh, C. L., and Hu, Y. C. (2016). Healing of osteoporotic bone defects by baculovirus-engineered bone marrow-derived MSCs expressing MicroRNA sponges. Biomaterials 74, 155-166. doi: 10.1016/j.biomaterials.2015. 09.046

Liang, W., Zhuo, X., Tang, Z., Wei, X., and Li, B. (2015). Calcitonin gene-related peptide stimulates proliferation and osteogenic differentiation of osteoporotic rat-derived bone mesenchymal stem cells. Mol. Cell Biochem. 402, 101-110. doi: 10.1007/s11010-014-2318-6

Lv, Y. J., Yang, Y., Sui, B. D., Hu, C. H., Zhao, P., Liao, L., et al. (2018). Resveratrol counteracts bone loss via mitofilin-mediated osteogenic improvement of mesenchymal stem cells in senescence-accelerated mice. Theranostics $8,2387-$ 2406. doi: 10.7150/thno.23620

Mathavan, N., Turunen, M. J., Tagil, M., and Isaksson, H. (2015). Characterising bone material composition and structure in the ovariectomized (OVX) rat model of osteoporosis. Calcif. Tissue Int. 97, 134-144. doi: 10.1007/s00223-0159991-7

Mi, J., Xu, J., Yao, H., Li, X., Tong, W., Li, Y., et al. (2021). Calcitonin gene-related peptide enhances distraction osteogenesis by increasing angiogenesis. Tissue Eng. Part A 27, 87-102. doi: 10.1089/ten.TEA.2020.0009

Naot, D., and Cornish, J. (2008). The role of peptides and receptors of the calcitonin family in the regulation of bone metabolism. Bone 43, 813-818. doi: 10.1016/j. bone.2008.07.003

Naot, D., Musson, D. S., and Cornish, J. (2019). The activity of peptides of the calcitonin family in bone. Physiol. Rev. 99, 781-805. doi: 10.1152/physrev. 00066.2017

Niedermair, T., Schirner, S., Lasheras, M. G., Straub, R. H., and Grassel, S. (2020). Absence of alpha-calcitonin gene-related peptide modulates bone remodeling properties of murine osteoblasts and osteoclasts in an age-dependent way. Mech. Ageing Dev. 189:111265. doi: 10.1016/j.mad.2020.111265

NIH Consensus Development Panel on Osteoporosis Prevention, Diagnosis, and Therapy (2001). Osteoporosis prevention, diagnosis, and therapy. JAMA 285, 785-795. doi: 10.1001/jama.285.6.785

Peng, H., Yang, M., Guo, Q., Su, T., Xiao, Y., and Xia, Z. Y. (2019). Dendrobium officinale polysaccharides regulate age-related lineage commitment between osteogenic and adipogenic differentiation. Cell Prolif. 52:e12624. doi: 10.1111/ cpr. 12624

Picke, A. K., Campbell, G. M., Bluher, M., Krugel, U., Schmidt, F. N., Tsourdi, E., et al. (2018). Thy-1 (CD90) promotes bone formation and protects against obesity. Sci. Transl. Med. 10:eaao6806. doi: 10.1126/scitranslmed.aao6806

Pittenger, M. F., Mackay, A. M., Beck, S. C., Jaiswal, R. K., Douglas, R., Mosca, J. D., et al. (1999). Multilineage potential of adult human mesenchymal stem cells. Science 284, 143-147. doi: 10.1126/science.284.5411.143

Rachner, T. D., Khosla, S., and Hofbauer, L. C. (2011). Osteoporosis: now and the future. Lancet 377, 1276-1287. doi: 10.1016/S0140-6736(10)62349-5

Rosenfeld, M. G., Mermod, J. J., Amara, S. G., Swanson, L. W., Sawchenko, P. E., Rivier, J., et al. (1983). Production of a novel neuropeptide encoded by the calcitonin gene via tissue-specific RNA processing. Nature 304, 129-135. doi: $10.1038 / 304129 \mathrm{a} 0$
Russell, F. A., King, R., Smillie, S. J., Kodji, X., and Brain, S. D. (2014). Calcitonin gene-related peptide: physiology and pathophysiology. Physiol. Rev. 94, 10991142. doi: 10.1152/physrev.00034.2013

Schinke, T., Liese, S., Priemel, M., Haberland, M., Schilling, A. F., Catala-Lehnen, P., et al. (2004). Decreased bone formation and osteopenia in mice lacking alpha-calcitonin gene-related peptide. J. Bone Miner Res. 19, 2049-2056. doi: 10.1359/JBMR.040915

Shen, W., Chen, J., Gantz, M., Punyanitya, M., Heymsfield, S. B., Gallagher, D., et al. (2012). MRI-measured pelvic bone marrow adipose tissue is inversely related to DXA-measured bone mineral in younger and older adults. Eur. J. Clin. Nutr. 66, 983-988. doi: 10.1038/ejcn.2012.35

Sternini, C. (1992). Enteric and visceral afferent CGRP neurons. Targets of innervation and differential expression patterns. Ann. N. Y. Acad. Sci. 657, 170-186. doi: 10.1111/j.1749-6632.1992.tb22766.x

Thievent, A., Sena, S., Parlakian, A., Breuzard, G., Beley, A., Rochette, L., et al. (2005). Potential role of the neuropeptide CGRP in the induction of differentiation of rat hepatic portal vein wall. Peptides 26, 1567-1572. doi: 10.1016/j.peptides.2005.02.015

Tsujikawa, K., Yayama, K., Hayashi, T., Matsushita, H., Yamaguchi, T., Shigeno, T., et al. (2007). Hypertension and dysregulated proinflammatory cytokine production in receptor activity-modifying protein 1-deficient mice. Proc. Natl. Acad. Sci. U.S.A. 104, 16702-16707. doi: 10.1073/pnas.0705974104

Tuzmen, C., and Campbell, P. G. (2018). Crosstalk between neuropeptides SP and CGRP in regulation of BMP2-induced bone differentiation. Connect Tissue Res. 59(Suppl. 1), 81-90. doi: 10.1080/03008207.2017.1408604

Villa, I., Dal Fiume, C., Maestroni, A., Rubinacci, A., Ravasi, F., and Guidobono, F. (2003). Human osteoblast-like cell proliferation induced by calcitoninrelated peptides involves PKC activity. Am. J. Physiol. Endocrinol. Metab. 284, E627-E633. doi: 10.1152/ajpendo.00307.2002

Wang, L., Shi, X., Zhao, R., Halloran, B. P., Clark, D. J., Jacobs, C. R., et al. (2010). Calcitonin-gene-related peptide stimulates stromal cell osteogenic differentiation and inhibits RANKL induced NF-kappaB activation, osteoclastogenesis and bone resorption. Bone 46, 1369-1379. doi: 10.1016/j.bone.2009.11.029

Xu, Y., Xia, M., Chen, T., Yang, Y., Fu, G., Ji, P., et al. (2019). Inferior alveolar nerve transection disturbs innate immune responses and bone healing after tooth extraction. Ann. N. Y. Acad. Sci. 1448, 52-64. doi: 10.1111/nyas.14120

Yang, M., Guo, Q., Peng, H., Xiao, Y. Z., Xiao, Y., Huang, Y., et al. (2019). Kruppellike factor 3 inhibition by mutated lncRNA Reglcp results in human high bone mass syndrome. J. Exp. Med. 216, 1944-1964. doi: 10.1084/jem.20181554

Yoo, Y. M., Kwag, J. H., Kim, K. H., and Kim, C. H. (2014). Effects of neuropeptides and mechanical loading on bone cell resorption in vitro. Int. J. Mol. Sci. 15, 5874-5883. doi: 10.3390/ijms15045874

Yu, B., and Wang, C. Y. (2016). Osteoporosis: the result of an 'aged' bone microenvironment. Trends Mol. Med. 22, 641-644. doi: 10.1016/j.molmed. 2016.06.002

Yuan, H., Lauritsen, C. G., Kaiser, E. A., and Silberstein, S. D. (2017). CGRP monoclonal antibodies for migraine: rationale and progress. BioDrugs 31, 487-501. doi: 10.1007/s40259-017-0250-5

Zhang, Y., Xu, J., Ruan, Y. C., Yu, M. K., O’Laughlin, M., Wise, H., et al. (2016). Implant-derived magnesium induces local neuronal production of CGRP to improve bone-fracture healing in rats. Nat. Med. 22, 1160-1169. doi: 10.1038/ nm.4162

Conflict of Interest: The authors declare that the research was conducted in the absence of any commercial or financial relationships that could be construed as a potential conflict of interest.

Copyright (c) $2021 \mathrm{Li}, \mathrm{Qu}, \mathrm{Zhu}, \mathrm{Wang}, \mathrm{He}, \mathrm{Xie}, \mathrm{Wu}$ and Lu. This is an open-access article distributed under the terms of the Creative Commons Attribution License (CC BY). The use, distribution or reproduction in other forums is permitted, provided the original author(s) and the copyright owner(s) are credited and that the original publication in this journal is cited, in accordance with accepted academic practice. No use, distribution or reproduction is permitted which does not comply with these terms. 